\title{
Science Academies' Refresher Course in Experimental Physics
}

\author{
at \\ National Institute of Technology \\ Warrangal, Telangana State \\ January 09-24 2018 \\ Sponsored by \\ Indian Academy of Sciences, Bengaluru \\ Indian National Science Academy, New Delhi \\ The National Academy of Sciences, India, Allahabad
}

\begin{abstract}
A Refresher Course in Experimental Physics will be held at National Institute of Technology, Warangal, Telangana State from 9th January 2018 to 24th January, 2018 for the benefit of faculty involved in teaching undergraduate and postgraduate courses. Participants in this course will gain hands-on experience with about twenty five out of forty experiments, with a low-cost kit developed for the Indian Academy of Sciences, and manufactured by Ajay Sensors and Instruments in Bangalore. These experiments are in (a) mechanics, (b) heat, (c) electricity both DC and AC, (d) magnetism, (e) relaxation, (f) phase sensitive detection technique, and (g) non-linear dynamics.

Refresher courses in Experimental Physics held so far have been highly successful and the experiments have been included in about 150 institutions including universities, autonomous colleges, and advanced science institutions involved in education. Over 1800 participants have been trained so far and more than 250 kits have been sold. The course will be directed by Prof. C S Sunder, F.A.Sc., F.N.A.Sc., F.N.A. It may be noted that for career advancement under UGC regulations include Refresher Courses for getting API scores.
\end{abstract}

Applications are invited from teachers with experience in teaching undergraduate and postgraduate courses in Engineering and Physics. Motivated students of BSc and MSc Physics courses with keen interest in Experimental Physics may also apply. The number of seats will be about 30 . Selected participants will be provided with travel assistance (limited to three-tier A/c train fare), accommodation and local hospitality during the Course in addition to course material. Interested applicants must submit their application ONLINE by clicking on the following link

http://web-japps.ias.ac.in: 8080/Refreshcourse/RIIE.jsp

A copy of the application form signed by the applicant should also be sent by Post to the Course Coordinator, at the address given below. In case of teachers, the form must also be signed and stamped by the Head of the applicants Institution stating that leave will be sanctioned if the applicant is selected for the Course. A recommendation letter from a teacher is essential for student applicants. Scanned copies of the duly signed documents sent by e-mail will also be accepted.

Address for communication: Dr. P Abdul Azeem and Dr. T V Appa Rao, Course Coordinators, Refresher Course in Experimental Physics, Department of Physics, National Institute of Technology, Warangal 506004(TS). Email: drazeem2002@yahoo.com, tvraokmm@yahoo. co. in Phone: +91 8332969473.

Last date for the receipt of applications: 30 November 2017.

Selected participants will be informed by: 5 December 2017. 